\title{
Automated monitoring of vocal rutting activity in red deer (Cervus elaphus)
}

\author{
llya A. Volodin*, Elena V. Volodina, Olga S. Golosova
}

\begin{abstract}
Vocal performances represent an important part of advertising male reproductive potential in red deer. Stag total vocal activity in rut period was studied on daily and weekly basis in two translocated herds of Siberian red deer Cervus elaphus sibiricus, kept at two farms in Central Russia ("Tver" and "Kostroma"). On both farms, stag rutting calls were recorded for 5 min each hour of a 24-hour period for the duration of 70-day rut period of 2013 using two automated recording systems, with simultaneous recording ambient temperature. Spectrographic analysis revealed that total number of calls was 30 times higher at Tver than at Kostroma (4341 and 145 calls respectively). Although the correlation between the daily average ambient temperatures in both farms was positive and highly significant, the average numbers of calls per hour did not correlate between herds. Over the course of the season, calling activity was singlehumped at Tver and two-humped at Kostroma. In relation to daily activity patterns, the number of calls per hour had one peak between 18:00-09:00 at Tver and two peaks at Kostroma (between 07:00-09:00 and between 16:00-18:00). The estimation of the effect of ambient temperature together with the effect of the week during the rut and time of day revealed that temperature does not have a significant effect on the number of stag rutting calls in either herd. Substantial differences in stag vocal activity between the farms could be due to herd composition and time passed since translocation.
\end{abstract}

KEY WORDS: reproductive behavior; acoustic communication; automated recorders; rutting bugles; call rate.

Ilya A. Volodin [volodinsvoc@gmail.com], Department of Vertebrate Zoology, Faculty of Biology, Lomonosov Moscow State University, Vorobievy Gory, 1/12, Moscow 119991, Russia; Elena V. Volodina [volodinsvoc@mail.ru], Scientific Research Department, Moscow Zoo, B. Gruzinskaya, 1, Moscow 123242, Russia; Olga S. Golosova [golosova95@yandex.ru], Department of Vertebrate Zoology, Faculty of Biology, Lomonosov Moscow State University, Vorobievy Gory, 1/12, Moscow 119991, Russia.

\section{Автоматический мониторинг вокальной гонной активности у благородного оленя (Cervus elaphus)}

\section{И.А. Володин*, Е.В. Володина, О.С. Голосова}

РЕЗЮМЕ. Уровень вокальной активности составляет важную часть демонстрации репродуктивного потенциала у самцов благородного оленя. В этом исследовании была проанализирована вокальная активность самцов за весь период гона, а также посуточно и в течение каждой недели гона в двух происходящих с Алтая группировках сибирского марала Cervus elaphus sibiricus, содержащихся на двух фермах в Центральной России (группировки “Тверь” и “Кострома”). На обеих фермах гонные крики самцов были записаны по 5 минут каждый час в течение 70 суток в гонный период 2013 г. с помощью двух автоматических систем аудиозаписи, с одновременной регистрацией температуры воздуха. Спектрографический анализ показал, что суммарное число гонных криков самцов было в 30 раз выше в Твери, чем в Костроме (соответственно 4341 и 145 криков). Хотя корреляция между средними дневными температурами воздуха на обеих фермах была положительной и высоко достоверной, корреляция между группировками по среднему числу криков в час отсутствовала. Вокальная активность за гонный период была одновершинной в Твери и двухвершинной в Костроме. В суточной активности единственный пик вокальной активности наблюдался с 18:00 до 09:00 в Твери, и два пика в Костроме (с 07:00 до 09:00 и с 16:00 до 18:00). Оценка влияния температуры воздуха совместно с влиянием порядкового номера недели в течение гона и времени суток показали, что температура не влияет достоверно на число гонных криков самцов ни в одной из популяций. Ярко выраженные различия в вокальной активности самцов между этими фермами могли быть результатом состава популяций и времени, прошедшего со времени перемещения животных с Алтая в Центральную Россию.

КЛЮЧЕВЫЕ СЛОВА: репродуктивное поведение; акустическая коммуникация; автоматическая аудиозапись; гонные крики; вокальная активность. 


\section{Introduction}

During the rut, red deer (Cervus elaphus L., 1758) stags vocalize to compete with other stags for female harems. Rut vocal displays represent a part of courtship, as they shift the ovulation of hinds to earlier dates (McComb, 1987), facilitate mate search and search of free rutting grounds by stags, thus preventing stags from undesirable combats and energy costs for elucidating the age and rank of competitive males (CluttonBrock \& Albon, 1979; Reby \& McComb, 2003b; Reby et al., 2005). Rutting calls of stags advertise male quality (Bowyer \& Kitchen, 1987; Clutton-Brock \& Albon, 1979; Reby \& McComb, 2003a). Stag vocal performance includes two components: the acoustic pattern of rutting calls (Reby \& McComb, 2003a) and the vocal activity at short and long terms, as males in worse body condition end calling earlier (Clutton-Brock \& Albon, 1979).

Acoustic patterns of stag rutting calls have been thoroughly investigated across subspecies of red deer (Struhsaker, 1968; Bowyer \& Kitchen, 1987; Reby \& McComb, 2003a; Feighny et al., 2006; Kidjo et al., 2008; Frey et al., 2012; Hurtado et al., 2012; Bocci et al., 2013; Passilongo et al., 2013; Volodin et al., 2013, 2015a; Della Libera et al., 2015) and effects of variation of certain acoustic variables on receptive females and competing males were also investigated in detail for some subspecies of red deer (Reby et al., 2005; Charlton et al., 2007a, 2007b, 2008a, 2008b). Intensity and endurance of rut vocal activity also reflect reproductive potential of wild and farmed males (Pepin et al., 2001; Briefer et al., 2010; McPherson \& Chenoweth, 2012). Intraspecific variation of mating system can also affect the rutting activity pattern (Carranza et al., 1990, 1995; Smith-Flueck \& Flueck, 2006). In addition, more than one peak of estrus of hinds may prolong the rut completion (Guinness et al., 1971; Smith, 1994; García et al., 2002).

Stag vocal activity is often used for estimating the population size, roaring counts are often used as indices of red deer abundance (Douhard et al., 2013). Douhard et al. (2013), summarizing 31 years of deer counts in France, suggested that this method is poorly suited for monitoring abundance of red deer populations for three main reasons: 1) the counts do not consistently synchronous with the roaring peaks, 2) the presence of human counters disturb the animals, 3 ) because of potential weather effects on stag calling activity and on human counters. Censuses are made either by ear, one to a few censuses per rutting season (Douhard et al., 2013), or by attracting stags with luring instruments (Volodin et al., 2013). Other studies also show that stag vocal activity varies substantially throughout a 24-hour period, during the course of the season, and between years (Clutton-Brock \& Albon, 1979; Bowyer \& Kitchen, 1987; Pepin et al., 2001; Bocci et al., 2013; Volodin et al., 2013, 2015b).

Automated recording systems are potentially applicable for formal validation of red deer censuses by ear.
Whereas human observers can only count during a limited time, recorders can be programmed to work day and night throughout the entire rut and are not affected by weather, thus providing full-scale data on the roaring activity. In addition, presence of humans suppress animal activities (Obrist et al., 2010; Llusia et al., 2011), whereas recorders work in the lack of researchers. Previously, the automated recording systems have been used in a pilot study of vocal rutting activity of wild Siberian red deer (Cervus elaphus sibiricus Severtzov, 1872) stags (Volodin et al., 2013), in a pilot study of vocal rutting activity of Far-East red deer $(C$. $e$. xanthopygus Milne-Edwards, 1867) stags (Volodin et al., 2015b), for collecting calls from wild Iberian red deer (C. e. hispanicus Hilzheimer, 1909) for subsequent acoustic analyses (Volodin et al., 2015a) and for collecting calls of farmed Siberian red deer stags for subsequent acoustic analyses (Volodin et al., 2016).

Additional advantage of using automated recording systems is the possibility to simultaneously record ambient temperature. High ambient temperature negatively affect the total physical activity of males (Johnson et al., 1972; Fedosenko, 1980) and might negatively impact the number of calls made by wild European red deer stags in France (Douhard et al., 2013) and in Siberian and Far-East red deer in their natural habitats (Volodin et al., 2013, 2015b). Most unusual behavioral adaptations to the calling at high ambient temperatures were found in male Iberian red deer evolved, displaying the prominent protrusion of the tongue during the male roars, probably in order to increase the evaporative cooling (Frey et al., 2012). Another advantage of data, collected with automated recorders, compared to data collected during censuses by ear is that they can be stored at computer and analysed subsequently at any time. Moreover, the researcher or deer manager can select any part of recordings and analyse it separately from other massive, in accordance to the current task.

The Siberian subspecies of red deer includes large animals with withers height of stags up to $155 \mathrm{~cm}$ and body mass of stags up to $416 \mathrm{~kg}$ and of hinds up to 190 $\mathrm{kg}$ (Fedosenko, 1980). Wild Siberian red deer inhabits mountain taiga areas to the South-East of Ural Mountains in Russia, Kazakhstan and China including Altai, Sayan Mountains, Lake Baikal region up to southern Yakutia (Stepanova, 2010; Kuznetsova et al., 2012). Hinds give birth mostly in June, and the rut time accordingly lasts from the second-third week of September to the end of October (Fedosenko, 1980). The Siberian red deer is the most important cervid species among farmed production animals of Russia and Kazakhstan, as it is intensively bred for velvet antlers and meat since 40 s years of 19 th century to nowadays (Lunitsin \& Borisov, 2012). For instance, in Korean markets, the velvet antlers of this subspecies are considered to be of particularly good quality and command the highest prices (Kim et al., 2015).

The purpose of this study was to compare stag rutting vocal activity of two fenced herds of Siberian red deer kept on two farms situated under the same 
climatic conditions but differing by deer abundance and management. In each herd, we test whether calling rates change with ambient temperature, throughout the day and throughout the rut period.

\section{Materials and methods}

\section{Study sites, subjects and dates of record- ings}

Stag rutting calls were recorded during the rut period from 3rd September to 11th November, 2013 (for 70 days $=10$ weeks in total) in two farms located in Central Russia. Dates and mode of acoustic recording were the same in both farms, the "Tver" $\left(56^{\circ} 30^{\prime} \mathrm{N}\right.$, $\left.35^{\circ} 27^{\prime} \mathrm{E}\right)$ and the "Kostroma" $\left(58^{\circ} 24^{\prime} \mathrm{N}, 43^{\circ} 15^{\prime} \mathrm{E}\right)$, that are separated by a distance of $510 \mathrm{~km}$. Both farms keep pure Siberian red deer translocated from velvet antler farms of Altai Territory (Southern Siberia, Russia). The Tver herd (approximately 400 animals in total, 0.08 deer/ha) originated in 2006 from a few dozen Siberian red deer released into a 5000-hectare enclosed property covered by forest with large fields (former agriculture grounds), with provision of supplementary food only in winter, out of rut period. The Kostroma herd (108 animals in total) originated in 2010 from a few dozen of Siberian red deer released into a 70-hectare enclosed property, with provision of supplementary food from the beginning of autumn to end of spring, i.e. enveloping the rut period. This farm was covered by old gardens, forest and bushes, with large fields (former agriculture grounds). The Kostroma farm territory was separated in two equal parts with wire mesh, one part for keeping 35 adult stags and another part for hinds and their young. During data collection, 5 adult stags were released to the part of hinds for breeding, so the animal density in this part was 2.2 deer/ha. Territory in Tver is larger, and in this sense it is more natural. Otherwise both localities are strongly different by conditions from the natural situation: less continental climate compared to natural habitats; forested plains instead of mountain taiga; large herds closed on a limited territory instead of widely dispersed stags with small harems of 1-3 hinds in nature (Fedosenko, 1980, Volodin et al., 2013).

\section{Data collection}

We used two (one on each farm) stationary automated recording systems Song Meter SM2+ (Wildlife Acoustics Inc., Maynard, MA, USA) for acoustic recordings $(22.05 \mathrm{kHz}, 16 \mathrm{bit}$, stereo). Each recording system was equipped with two omni-directional microphones, fixed horizontally at 180 degrees to each other. The automated recording systems were mounted on trees at $2 \mathrm{~m}$ above the ground in places of most active rut. In Kostroma herd, where the enclosure was divided in two equal parts, the recording device was placed at the border of the two parts to collect calls from both groups of males. The recording schedule was set at 5 min per hour, $120 \mathrm{~min}$ in total per $24 \mathrm{~h}$, with simultaneous registration of ambient temperature once each hour (precision $\pm 1^{\circ} \mathrm{C}$ ). The total of 33605 -min digital sound files provided $280 \mathrm{~h}$ of recordings throughout the $70 \mathrm{~d}$ period of recording.

Study design imitated data collection from the wild populations, on which only scarce data are available. This kind of design was selected because research permits from property owners only allowed to establish the automated recording systems in places where stags were most active during the rut. After the rut completion, the equipment was removed by the farm owners and returned to researchers. Any investigation of herd structure and stag harem behavior was impossible during this study. At Kostroma farm, information about the number of animals, their sex and ages was obtained from the farm owners, whereas at Tver farm, the owners could only report approximate number of animals and no information about the herd structure.

On natural breeding grounds in Siberia, rutting calls of male Siberian red deer propagate by a distance of 1.5 $\mathrm{km}$ (Volodin et al., 2013). The automated recording systems were set at maximum possible sensitivity and potentially collected all stag rutting calls from the distance of about $1 \mathrm{~km}$. So, we suppose that for the 70 hectare territory for the Kostroma farm, all stag calls were captured by the Song Meter SM2+. At the same time, potentially not all stag calls were captured from the larger territory for the Tver farm.

\section{Data analysis and statistics}

All sound files were viewed and analyzed through Avisoft SASLab Pro software (Avisoft Bioacoustics, Germany, Berlin) main window, and the number of calls contained in each file (irrespective of their quality) was counted (Fig. 1). For estimating seasonal effects on stag vocal activity, we calculated the daily mean call number per hour for each 24-hour period (as total number of calls/day divided by 24) across $70 \mathrm{~d}$ of recording. Also, for estimating effects of ambient temperature on stag vocal activity in the course of the season, we calculated the daily mean ambient temperature for each 24-hour period by 24 registrations (one registration per hour).

For evaluating the 24-hour activity patterns of stag vocalizations, we calculated the mean number of calls per hour for each 24-hour period (average by 70 sound files for each hour across the $70 \mathrm{~d}$ recording period). Also, we calculated the hourly mean ambient temperature (averaged by 70 registrations for each time of day across the $70 \mathrm{~d}$ of recording).

All statistic analyses were made with STATISTICA v. 6.0 (StatSoft Inc., Tulsa, OK, USA). Significance levels were set at 0.05 , and two-tailed probability values are reported. We used the Pearson correlation for evaluating a possible effect of ambient temperature on the hourly vocal activity within herd and for compari- 

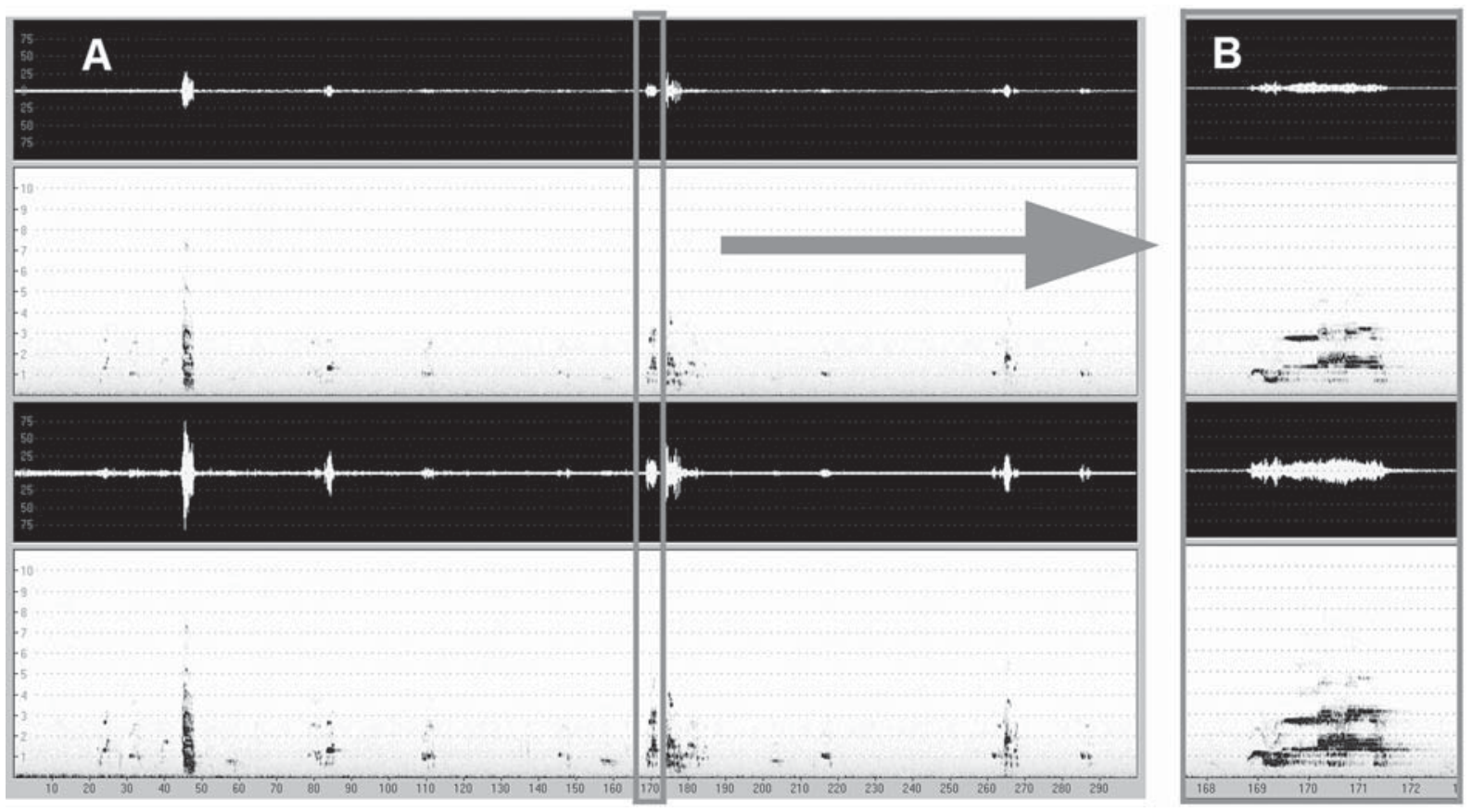

Fig. 1. Visualizing stag rutting calls of Siberian red deer recorded in stereo mode with automated recording system using Song Meter SM2+. Axis X represents time in seconds; axis Y represents frequency in kilohertz. (A) Spectrogram of one 5-min-long sound file. (B) Expanded spectrogram of the selected fragment with a rutting call.

son the daily mean ambient temperatures and the average number of calls per hour between Tver and Kostroma herds. For estimating the joint effect of the period of rut, time of day and ambient temperature on the number of calls per hour, we subdivided the entire recording period chronologically into 10 week segments. We used the multiple analysis of variance (General Linear Models module with as default settings) with Tukey HSD test, taking the sequential week number as fixed categorical factor "season", the time of day (h) as fixed categorical factor "time of day" and the ambient temperature as continual factor "temperature".

We provided effect size (ES) statistics to measure the strength of an effect in addition to statistical significance. We calculated the effect size for GLM using $\eta^{2}$ $\left(\eta^{2}=0.01\right.$ for a small effect, 0.06 for a medium effect and 0.14 for a large effect; Cohen, 1992; Fritz et al., 2012). For the correlation analyses, the correlation coefficient itself was an estimation of the effect size $(r=$ 0.1 for a small effect, 0.3 for a medium effect and 0.5 for a large effect; Fritz et al., 2012).

\section{Results}

The total number of rutting calls recorded throughout the $70 \mathrm{~d}$ of recording was 30 times higher at Tver than at Kostroma (4341 and 145 calls respectively). The daily mean ambient temperatures correlated between the two study sites positively and highly significantly ( $r=0.85, P<0.001, N=70$, large ES), but no correlation was found in the average number of calls per hour between Tver and Kostroma herds ( $r=0.05$, $P=0.67, N=70$, no ES).

In the course of the $70 \mathrm{~d}$ of recording, the vocal activity changed differently between Tver and Kostroma farms (Fig. 2). While at Tver, the daily mean call number per hour significantly negatively correlated with daily mean ambient temperature $(r=-0.29, P=0.013$, $N=70$, small ES), at Kostroma, the correlation was non-significant ( $r=-0.15, P=0.20, N=70$, small ES). At Tver, the course of the daily mean call number per hour was single-humped and the highest vocal activity was found between 24 September and 21 October, peaked at 6 October. At Kostroma, the vocal activity was two-humped, showing small peaks at 22 September and 25 October, and being very low between the peaks (Fig. 2). At Tver, the daily mean number of calls per hour was related to time of day, with highest vocal activity between 18:00 and 09:00 (Fig. 3). At Kostroma, the daily mean call number per hour was high between 07:00-09:00 and between 16:00 and 18:00 (Fig. 3).

For Tver, the analysis of variance revealed effects of season $\left(F_{9,1646}=118.80, P<0.001, \eta^{2}=0.39\right.$, large ES) and time of day $\left(F_{23,1646}=8.99, P<0.001, \eta^{2}=0.11\right.$, medium ES), but not temperature $\left(F_{1,1646}=2.28, P=\right.$ $0.13, \eta^{2}=0.001$, no ES), on the average number of calls per hour. The average number of calls per hour was significantly higher at 4th, 5th, 6th and 7th weeks (from 24 September to 21 October) compared to any other week (Tukey HSD test, $P<0.001$ ). By the call number per hour values, the weeks of high vocal activity (4th- 


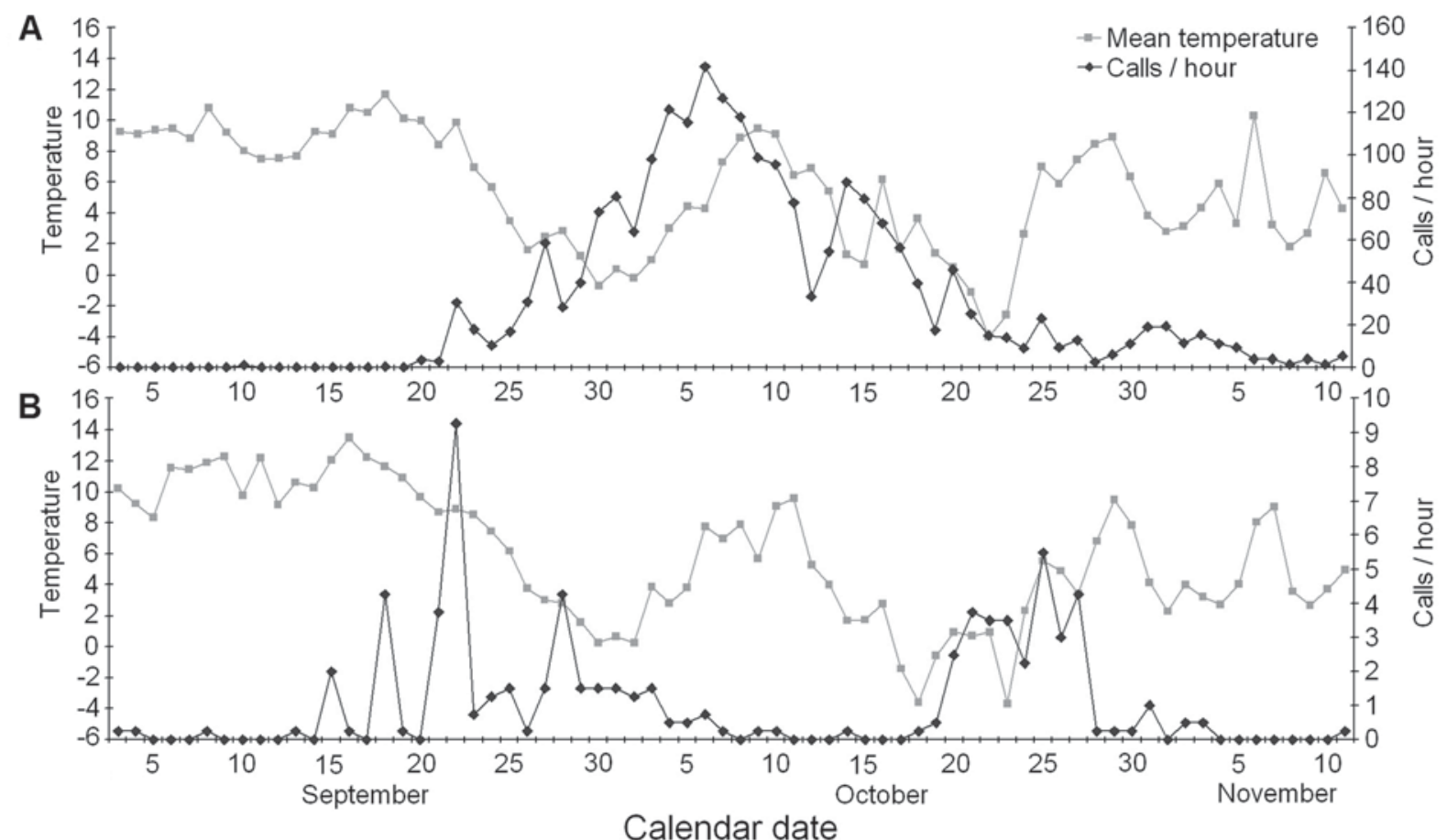

Fig. 2. Graphs by weeks (in the course of the $70 \mathrm{~d}$ recording period during the rut) of the Siberian red deer stag vocal activity and of the mean daily ambient temperature in two study farms: (A) Tver and (B) Kostroma. Designations: Calls/hour - the daily mean call number per hour (averaged by 24 sound files recorded per $24 \mathrm{~h}$ ); Mean temperature — the daily mean ambient temperature (averaged by 24 registrations taken once per hour).

7th wks), differed significantly among each other, whereas the weeks of low vocal activity (1-3 wks and 8-10 wks), not differed significantly among each other (Fig. 4). The number of calls per hour was significantly higher during periods from 18:00 to 09:00 h compared
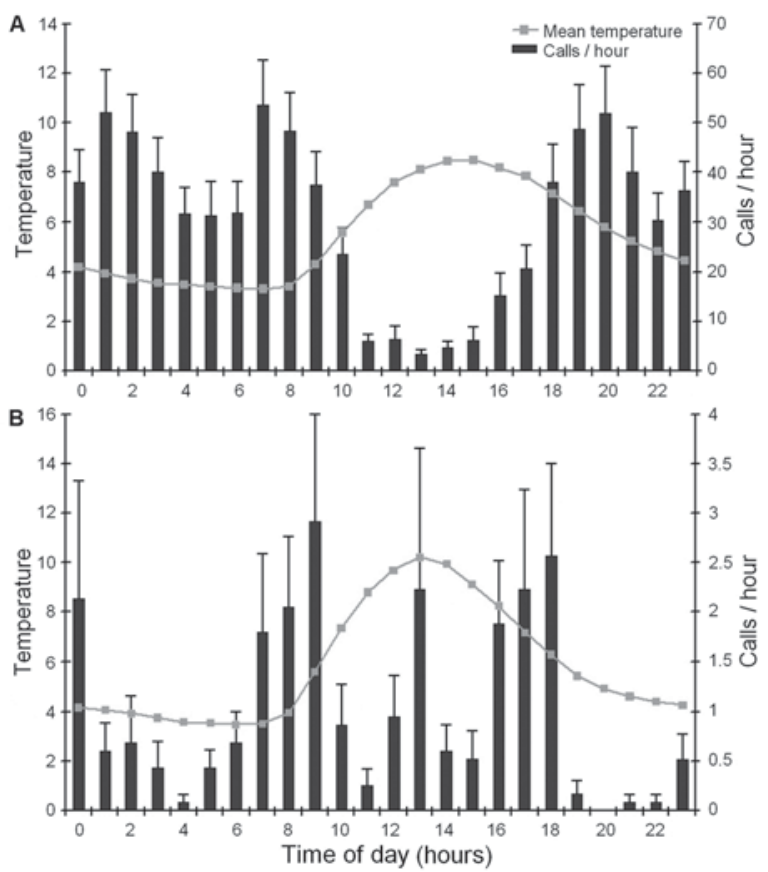

to those from 11:00 to 15:00 h (Tukey HSD test, $P<$ $0.05)$. At 10:00, 16:00 and 17:00 h, the number of calls per hour was intermediate and did not differ significantly from either the highest vocal activity periods $(18: 00-09: 00 \mathrm{~h})$, or the lowest vocal activity periods (11:00-15:00 h).

For Kostroma, the analysis of variance revealed effects of season $\left(F_{9,1646}=7.46, P<0.001, \eta^{2}=0.04\right.$, small ES) and time of day $\left(F_{23,1646}=2.29, P<0.001, \eta^{2}\right.$ $=0.03$, small ES), but not temperature $\left(F_{1,1646}=2.09, P\right.$ $=0.15, \eta^{2}=0.001$, no ES), on the average number of calls per hour. The average number of calls per hour was significantly higher in the 3rd and 8th weeks compared to 1 st, 2nd, 6th, 9th and 10th weeks (Tukey HSD test, $P<0.01$ ) (Fig. 4). The number of calls per hour in the $3 \mathrm{rd}$ and 8 th weeks was not statistically different to the 4 th, 5 th and 7 th weeks (Tukey HSD test, $P>0.05$ ). Among times of day, Tukey HSD test did not reveal significant differences for any comparison.

Fig. 3. Time of day (hourly) graphs of the Siberian red deer stag vocal activity and of the mean hourly ambient temperature in two study farms: (A) Tver and (B) Kostroma. Designations: Calls/hour - the mean number of calls per time of day (averaged by 70 digital sound files for each time of day across the $70 \mathrm{~d}$ rut period), whiskers indicate SE; Mean temperature - the hourly mean ambient temperature (averaged by 70 registrations for each time of day across the $70 \mathrm{~d}$ rut period). 

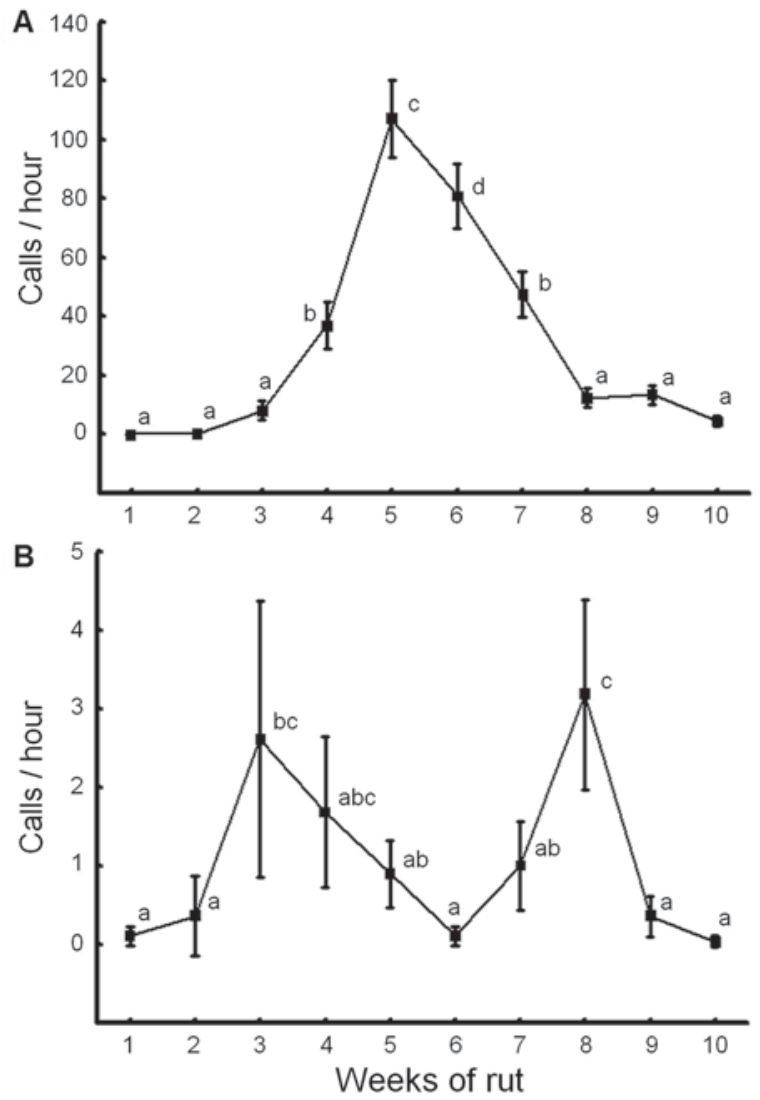

Fig. 4. The number of calls per hour (mean $\pm 2 \mathrm{SE}$ ) in the course of 10 weeks throughout the $70 \mathrm{~d}$ recording period during the rut of Siberian red deer stags in two study farms: (A) Tver and (B) Kostroma. Results for comparison of vocal activity between weeks (GLM with Tukey HSD test) are given with letters; means sharing the same letter are not significantly different.

\section{Discussion}

In the two Siberian red deer farms, the daily and weekly vocal activities were strongly different in spite of similar temperature in both sites. The total number of the recorded calls was 30 times greater at Tver farm compared to Kostroma farm. These differences might be explained by differences in the herd composition and farm management. The Tver farm had low density (0.08 individuals/ha), contained many mature stags that were kept 8 years within this fenced territory; hunting was practiced, though minimally (only two gunshot sounds were registered in the total amount of recordings). The Kostroma farm, with a high density (2.2 individuals/ha) contained many young stags (younger than 3 years) that were translocated from Siberia within the last 3 years. In addition, herd structure was very different between these two farms. In Tver, all stags were permanently kept together with hinds on the entire farm territory, whereas in Kostroma, only 5 stags were released for breeding to the hinds. Several studies have shown that rut behavior is influenced by animal density and population structure (Clutton-Brock \& Albon, 1979; Bowyer \& Kitchen, 1987; Clutton-Brock et al., 1997; Yoccoz et al., 2002) as well as by resource distribution (Carranza et al., 1995). All studies on vocal activity of rutting male red deer were made with individually unidentified animals, on average for each territory. The problem of recognition of individual unmarked red deer callers is actual, but not yet resolved for neither automated nor manual acoustic recordings. Possible, this problem can be partially resolved by individual collars with compact recording devices, applied previously for recording the sounds produced by mule deer Odocoileus hemionus females during ruminating (Lynch et al., 2015). Potentially, these devices can be applied for captive or semi-captive red deer, however their application for natural populations is restricted by the necessity of obligate capturing the animals for mounting on them the collars with the recording units.

During the rut period, a single prominent peak of roaring activity for the duration of 20-30 days was detected in Tver. Similar one-humped pattern of rut vocal activity was reported for other populations of red deer, both for free-ranging (Clutton-Brock \& Albon, 1979; Bocci et al., 2013) and farmed deer (Pepin et al., 2001). The pattern of vocal activity across rut with two well-defined peaks and a depression between them, detected in Kostroma in this study, was not reported anywhere, excluding the study by Bocci et al. (2013) that revealed a smaller additional peak approximately 45 days after the main peak of roaring activity in freeranging Italian Alpine population of red deer. Additional peaks of roaring activity during the rut could be influenced by female estrus. When health conditions are poor or when supplementary feeding is applied, females may have a few subsequent estrus cycles (21 days or longer, given they were not bred successfully the first time, thus they ovulate again (Smith, 1994; García et al., 2002) and this could explain the two peaks, separated by approximately 32 days, that we observed at Kostroma farm.

High stag roaring activity at the peak of the rut (up to 300-400 roars/hour) seems to be characteristic for free-ranging populations of red deer (Bocci et al., 2013). For some harem-holding stags, the number of roars per hour reached up to 150 in free-ranging populations (Clutton-Brock \& Albon, 1979) and 60-70 in farmed populations (Pepin et al., 2001). These data are comparable to our results for Tver farm, where the animals were ranging at large territory.

Intraspecific variation of the mating system is known to exist in red deer (Carranza et al., 1995). However, a denied access to the territory of the study farms during the rut did not allow us to estimate whether adult males show territoriality, mobile harem formation, or a combination of the two mating systems during the rut at these two sites. Therefore, our study reminded the counts in natural populations, for estimating the population size where forest managers do not know much about the deer populations and are mostly blind to their social 
structure (Douhard et al., 2013; Volodin et al., 2013, 2015b). Also, methods of automated recordings applied in this study, are blind to individual identity of the callers. As individual identity of stags cannot be identified by spectrograms created from automated recordings, it is impossible to count, how many roars per individual stag indeed were produced. In addition, studies with individually identified red deer stags revealed only a limited potential of male rutting calls to encode individual identity (Bocci et al., 2013; Passilongo et al., 2013; Della Libera et al., 2015) along to the prominent instability of individual acoustic traits during the rut (Reby et al., 2006).

We detected the relation between stag roaring activity and time of day only in Tver, but not in Kostroma. Other studies also report variable effects of time of day on the rutting vocal activity. In Alpine red deer population in Italy, stags vocalized primarily at nights and early in the morning, peaked at 05:00-07:00 (Bocci et al., 2013). However, at the Isle of Rum population, stags vocalized primarily during the day (Clutton-Brock \& Albon, 1979), as well as farmed stags in France (Pepin et al., 2001). In our study, the diurnal cycle of stag calling in Kostroma was shifted to the time of animal feeding occurring about 09:00 and about 17:00 h. Probably, the feeding provoked hinds to move to the feeders and thus could activate the calling of stags, which tried to control their harems (Smith-Flueck \& Flueck, 2006). Intermittent roaring throughout the day was also observed by Clutton-Brock \& Albon (1979).

The estimation of the effect of ambient temperature together with the effect of the week during the rut period and time of day revealed that temperature does not have a significant effect on the number of stag rutting calls in either farm. Effect size also indicates a stronger influence of the week during the rut and of time of day compared to the effect of ambient temperature either in Tver or in Kostroma. Although correlation analysis revealed a significant effect of temperature on vocal activity during the rut in Tver, the low effect size indicates that the influence of temperature was also weak. Consistently, Bocci et al. (2013) did not find effects of ambient temperature on calling activity in red deer stags during two rutting seasons. However, the 31-year study by Douhard et al. (2013) demonstrated a negative relationship between temperature and roaring count index, which can be explained by a reduction of animal activity when temperature increases. Similarly, our previous pilot study of rutting vocal activity in free-ranging Siberian and Far-East red deer revealed a negative relationship between call number produced by stags and air temperature (Volodin et al., 2013, 2015b)

In this study comparative data have been collected using the automated recordings method. The use of automated recording systems opens a possibility of at least partial validation of roaring counts by ear and of better estimating the relative number of roars in the course of the season. These systems allow to negotiate effects of such factors as dates for roaring counts, fatigue of researchers (affecting their attention), or effect of experience and personality of human counters. The automated recording systems work autonomously, in the absence of humans, by predetermined schedule during day and night and day after day. This allows making longitudinal recordings throughout the rut period. In addition, this allows avoiding or keeping at minimum the undesirable effect of human presence on vocal behavior of animals in the site of recordings. A substantial advantage of these systems is that the recordings can be stored and re-examined at any time. However, the important disadvantage is impossibility to individually identify the animals and count their number.

During the strong wind and rainfall, loud stag calls (recorded at high call-to-noise ratio) still could be detected from spectrograms. The wind and rainfall might affect the roaring activity of stags, although they may even stronger affect the ability of human counters to hear these calls (Bobek et al., 1986; Pepin et al., 2001; Douhard et al., 2013). Thus, the automated recording systems only partly resolve this problem, as the noise of wind and rain interfere detection soft calls at spectrograms of the acoustic recordings.

ACKNOWLEDGEMENTS. We thank the owners of the deer facilities N. Romanenko, O. Semenkov and the farm manager A. Ermolaev for their help and support. We thank Prof. A. Danilkin and M. Madeisky for their promotions with data collection. We are sincerely grateful to the anonymous reviewer and to Prof. A. Nahlik for their valuable comments to the manuscript. Data for this study were collected in accordance with the Guidelines for the Use of Animals in Research (Animal Behaviour, 2006, 71: 245-253). No animal has suffered somehow due to the data collection. The study was supported by the Russian Foundation for Basic Research, grant 15-04-06241a.

\section{References}

Bobek B., Perzanowski K. \& Zielinski J. 1986. Red deer population census in mountains: testing of an alternative method // Acta Theriologica. Vol.31. No.31. P.424-431.

Bocci A., Telford M. \& Laiolo P. 2013. Determinants of the acoustic behaviour of red deer during breeding in a wild alpine population, and implications for species survey // Ethology, Ecology \& Evolution. Vol.25. No.1. P.52-69.

Bowyer R.T. \& Kitchen D.W. 1987. Sex and age-class differences in vocalizations of Roosevelt elk during rut // American Midland Naturalist. Vol.118. No.2. P.225-235.

Briefer E., Vannoni E. \& McElligott A.G. 2010. Quality prevails over identity in the sexually selected vocalisations of an ageing mammal // BMC Biology. Vol.8. No.35. P.1-15.

Carranza J., Alvarez F. \& Redondo T. 1990. Territoriality as a mating strategy in red deer// Animal Behaviour. Vol.40. No.1. P.79-88.

Carranza J., Garcia-Munoz A.J. \& Dios Vargas J. 1995. Experimental shifting from harem defense to territoriali- 
ty in rutting red deer // Animal Behaviour. Vol.49. No.2. P.551-554

Charlton B.D., McComb K. \& Reby D. 2008a. Free-ranging red deer hinds show greater attentiveness to roars with formant frequencies typical of young males // Ethology. Vol.114. No.10. P.1023-1031.

Charlton B.D., Reby D. \& McComb K. 2007a. Female red deer prefer the roars of larger males // Biology Letters. Vol.3. No.4. P.382-385.

Charlton B.D., Reby D. \& McComb K. 2007b. Female perception of size-related formant shifts in red deer ( $\mathrm{Cer}$ vus elaphus) // Animal Behaviour. Vol.74. No.4. P.707714.

Charlton B.D., Reby D. \& McComb K. 2008b. Effect of combined source (F0) and filter (formant) variation on red deer hind responses to male roars // Journal of the Acoustical Society of America. Vol.123. No.5. P.29362943.

Clutton-Brock T.H. \& Albon S.D. 1979. The roaring of red deer and the evolution of honest advertising // Behaviour. Vol.69. No.3-4. P.145-170.

Clutton-Brock T.H., Rose K.E. \& Guinness F.E. 1997. Density-related changes in sexual selection in red deer // Proceedings of the Royal Society of London. Series B. Vol.264. No.1387. P.1509-1516.

Cohen J. 1992. A power primer // Psychological Bulletin. Vol.112. No.1. P.155-159.

Della Libera M., Passilongo D. \& Reby D. 2015. The acoustics of male rutting roars in the endangered population of Mesola red deer Cervus elaphus italicus // Mammalian Biology. Vol.80. No.5. P.395-400.

Douhard M., Bonenfant C., Gaillard J.-M., Hamann J.-L. \& Jacques M.G. 2013. Roaring counts are not suitable for the monitoring of red deer Cervus elaphus population abundance // Wildlife Biology. Vol.19. No.1. P.94-101.

Fedosenko A.K. 1980. [The maral (ecology, behaviour, management)]. Alma-Ata: Nauka. 200 p. [in Russian].

Feighny J.J., Williamson K.E. \& Clarke J.A. 2006. North American elk bugle vocalizations: male and female bugle call structure and context // Journal of Mammalogy. Vol.87. No.6. P.1072-1077.

Frey R., Volodin I., Volodina E., Carranza J. \& TorresPorras J. 2012. Vocal anatomy, tongue protrusion behaviour and the acoustics of rutting roars in free-ranging Iberian red deer stags (Cervus elaphus hispanicus) // Journal of Anatomy. Vol.220. No.3. P.271-292.

Fritz C.O., Morris P.E. \& Richler J.J. 2012. Effect size estimates: current use, calculations, and interpretation // Journal of Experimental Psychology. Vol.141. No.1. P.218.

García A.J., Landete-Castillejos T., Garde J.J. \& Gallego L. 2002. Reproductive seasonality in female Iberian red deer (Cervus elaphus hispanicus) // Theriogenology. Vol.58. No.8. P.1553-1562.

Guinness F., Lincoln G.A. \& Short R.V. 1971. The reproductive cycle of the female red deer, Cervus elaphus L. // Reproduction. Vol.27. No.3. P.427-438.

Hurtado A.M., Smith-Flueck J.M. \& Black-Decima P. 2012. Comparison of vocalisations of introduced European red deer stags (Cervus elaphus) in north-western Patagonia
(Argentina) with native European populations // Animal Production Science. Vol.52. No.8. P.714-719.

Johnson K.G., Maloiy G.M.O. \& Bligh J. 1972. Sweat gland function in the red deer (Cervus elaphus) // American Journal of Physiology. Vol.223. No.3. P.604-607.

Kidjo N., Cargnelutti B., Charlton B.D., Wilson C. \& Reby D. 2008. Vocal behaviour in the endangered Corsican deer: description and phylogenetic implications // Bioacoustics. Vol.18. No.2. P.159-181.

Kim Y.H., Lee J.W., Chae S., Moon S.H., Do E.J., Oh S.E., Zhang G.J. \& Lee M.Y. 2015. Development of a PCRbased assay to differentiate Cervus elaphus sibiricus from Cervus antlers // Journal of the Korean Society for Applied Biological Chemistry. Vol.58. No.1. P.61-66.

Kuznetsova M.V., Danilkin A.A. \& Kholodova M.V. 2012. Phylogeography of red deer (Cervus elaphus): analysis of mtDNA cytochrome $b$ polymorphism // Biology Bulletin. Vol.39. No.4. P.323-330.

Llusia D., Marquez R. \& Bowker R. 2011. Terrestrial sound monitoring systems, a methodology for quantitative calibration // Bioacoustics. Vol.20. No.3. P.277-286.

Lunitsin V.G. \& Borisov N.P. 2012. [Deer management for velvet antlers production in Russia]. Barnaul: VNIIPO. 1000 p. [In Russian].

Lynch E., Northrup J.M., McKenna M.F., Anderson C.R., Angeloni L. \& Wittemyer G. 2015 Landscape and anthropogenic features influence the use of auditory vigilance by mule deer // Behavioral Ecology. Vol.26. No.1. P.75-82.

McComb K. 1987. Roaring by red deer stags advances the date of oestrus in hinds // Nature. Vol.330. No.6149. P.648-649.

McPherson F.J. \& Chenoweth P.J. 2012. Mammalian sexual dimorphism // Animal Reproduction Science. Vol.131. No.3-4. P.109-122.

Obrist M.K., Pavan G., Sueur J., Riede K., Llusia D. \& Marquez R. 2010. Bioacoustics approaches in biodiversity inventories // Eymann J., Degreef J., Häuser C., Monje J.C., Samyn Y. \& VandenSpiegel D. (eds.). Manual on field recording techniques and protocols for all taxa biodiversity inventories and monitoring. Vol.8. Part.1. Brussels: Abc Taxa. P.68-99.

Passilongo D., Reby D., Carranza J. \& Apollonio M. 2013. Roaring high and low: composition and possible functions of the Iberian stag's vocal repertoire // PLoS ONE. Vol.8. No.5. e63841.

Pepin D., Cargnelutti B., Gonzalez G., Joachim J. \& Reby D. 2001. Diurnal and seasonal variations of roaring activity of farmed red deer stags // Applied Animal Behaviour Science. Vol.74. No.3. P.233-239.

Reby D., Andre-Obrecht R., Galinier A., Farinas G. \& Cargnelutti B. 2006. Cepstral coefficients and hidden Markov models reveal idiosyncratic voice characteristics in red deer (Cervus elaphus) stags // Journal of the Acoustical Society of America. Vol.120. No.6. P.4080 4089.

Reby D. \& McComb K. 2003a. Anatomical constraints generate honesty: acoustic cues to age and weight in the roars of red deer stags // Animal Behaviour. Vol.65. No.3. P.519-530. 
Reby D. \& McComb K. 2003b. Vocal communication and reproduction in deer // Advances in the Study of Behaviour. Vol.33. P.231-264.

Reby D., McComb K., Cargnelutti B., Darwin C.J., Fitch W.T. \& Clutton-Brock T.H. 2005. Red deer stags use formants as assessment cues during intra-sexual agonistic interactions // Proceedings of the Royal Society London. Series B. Vol.272. No.1566. P.941-947.

Smith B.L. 1994. Out-of-season births of elk calves in Wyoming // Prairie Naturalist. Vol.26. No.2. P.131-136.

Smith-Flueck J.M. \& Flueck W.T. 2006. Defense of territories by rutting red deer stags, Cervus elaphus, in Patagonia, Argentina // Bartoš L., Dušek A., Kotrba R. and Bartošová-Víchová J. (eds.). Advances in deer biology. Praha: Research Institute of Animal Production. P.174178.

Stepanova V.V. 2010. Expansion of geographic range of red deer in Yakutia // Russian Journal of Biological Invasions. Vol.1. No.1. P.30-36.

Struhsaker T.T. 1968. The behavior of the elk (Cervus canadensis) during the rut // Zeitschrift für Tierpsychologie. Vol.24. No.1. P.80-114.

Volodin I.A., Matrosova V.A., Volodina E.V., Garcia A.J., Gallego L., Márquez R., Llusia D., Beltrán J.F. \& Lan-
dete-Castillejos T. 2015a. Sex and age-class differences in calls of Iberian red deer during the rut: reversed sex dimorphism of pitch and contrasting roars from farmed and wild stags // Acta Ethologica. Vol.18. No.1. P.1929.

Volodin I.A., Sibiryakova O.V. \& Volodina E.V. 2016. Sex and age-class differences in calls of Siberian wapiti Cervus elaphus sibiricus // Mammalian Biology. Vol.81. No.1. P.10-20.

Volodin I.A., Volodina E.V., Frey R. \& Maymanakova I.L. 2013. Vocal activity and acoustic structure of the rutting calls of Siberian wapiti (Cervus elaphus sibiricus) and their imitation with a hunting luring instrument // Russian Journal of Theriology. Vol.12. No.2. P.99-106.

Volodin I.A., Volodina E.V., Sibiryakova O.V., Naidenko S.V., Hernandez-Blanco J.A., Litvinov M.N. \& Rozhnov V.V. 2015b. Vocal activity of the red deer and the acoustic structure of its rutting calls in the Russian Far East // Doklady Biological Sciences. Vol.462. No.1. P.144-147.

Yoccoz N.G., Mysterud A., Langvatn R. \& Stenseth N.C. 2002. Age- and density-dependent reproductive effort in male red deer // Proceedings of the Royal Society of London. Series B. Vol.269. No.1500. P.1523-1528. 